\title{
Posterior subcapsular cataracts, bruises and hoarseness in children with asthma receiving long-term treatment with inhaled budesonide
}

\author{
L. Agertoft, F.E. Larsen, S. Pedersen
}

Posterior subcapsular cataracts, bruises and hoarseness in children with asthma receiving long-term treatment with inhaled budesonide. L. Agertoft, F.E. Larsen, S. Pedersen. (OERS Journals Ltd 1998.

ABSTRACT: We assessed the effect of long-term treatment with inhaled budesonide (BUD) on the occurrence of posterior subcapsular cataracts (PSC), bruises and hoarseness in children with asthma.

Slit lamp examinations were performed in 157 asthmatic children treated with inhaled BUD at a mean daily dose of 504 $\mu \mathrm{g}$ (range 189-1,322 $\mu \mathrm{g}$ ) for 3-6 yrs (mean 4.4 yrs). Measurements were compared with 111 age-matched children with asthma, who had never received treatment of exogenous corticosteroids (control group). The children were examined for bruises, their tendency to bruise and occurrence of voice changes.

No incidents of PSC ascribable to BUD treatment were seen. One patient in the BUD group had been diagnosed with PSC before the study and this was still present. There were no statistically significant differences in number of bruises between the two groups $(B U D=3.3$, controls $=3.2 ; p=0.70)$, area covered by bruises $\left(B U D=10 \mathrm{~cm}^{2}\right.$, controls $\left.=10.1 \mathrm{~cm}^{2} ; \mathrm{p}=0.97\right)$, tendency to bruise $(\mathrm{BUD}=5 / 10$, controls $=5 / 10)$ or occurrence of hoarseness $(B U D=20 \%$, controls $=21 \% ; p=0.92)$. Furthermore, there was no correlation between the occurrence of bruises or tendency to bruise and duration of treatment, accumulated or current dose of BUD.

A 3-6 yr treatment of children with inhaled budesonide at an average daily dose of about $500 \mu \mathrm{g}$ is not associated with an increased occurrence of posterior subcapsular cataract, bruises, tendency to bruise, hoarseness or other noticeable voice changes.

Eur Respir J 1998; 12: 130-135.
Dept of Paediatrics, Kolding Hospital, Kolding, Denmark.

Correspondence L. Agertoft

Dept of Paediatrics

Kolding Hospital

DK-6000 Kolding

Denmark

Fax: 4575542680

Keywords: Bruises

cataracts

children

hoarseness

inhaled steroids

Received: August 181997

Accepted after revision March 71998
Advances in our understanding of the pathophysiology of asthma as an inflammatory disease, even in patients with mild illness, have resulted in the early use of inhaled corticosteroids for optimal treatment of both adults and children [1-3]. Several controlled clinical trials have established the efficacy of inhaled corticosteroids in improving virtually all outcome measures in asthma to a greater extent than any other antiasthma drug $[2,4]$. This change in therapy has occurred more rapidly in the adult asthmatic population than in the paediatric, mainly because paediatricians (and parents) are still concerned about the potential adverse effects of long-term treatment with inhaled corticosteroids in growing children.

Systemic corticosteroids have been shown to be associated with an increased occurrence of cataracts and bruises in children and adults [5-8]. Moreover, long-term, highdose inhaled corticosteroid therapy in adults has been associated with dermal thinning and increased occurrence of bruises and hoarseness [9-11]. At present, our knowledge is rather sparse about the occurrence of posterior subcapsular cataracts (PSC), bruises and hoarseness in children with asthma receiving continuous long-term treatment with inhaled corticosteroids.
Several studies have evaluated the influence of inhaled corticosteroids on markers of collagen formation and degradation [12-15]. Generally, the results from these studies have been reassuring: doses of inhaled corticosteroids producing optimal disease control in the majority of patients are not associated with any detectable effect on these markers, although significant changes have sometimes been reported with high-dose therapy. It remains to be established, however, whether these small changes in markers of collagen formation and degradation are clinically important.

The aim of the present study was to assess the occurrence of PSCs, bruises and hoarseness in children with asthma treated for at least 3 yrs with the inhaled corticosteroid budesonide, and to compare the findings with those of asthmatic children who had never received continuous treatment with exogenous corticosteroids.

\section{Patients and methods}

Children with persistent asthma and no other chronic disease were studied. The patients were well-known to our 
clinic as participants in an ongoing prospective, long-term (several years) controlled study on the effect of budesonide on growth and lung function [1]. The present investigation was added as a part of the recordings made in the prospective study at a time when all children had been followed for at least 3 yrs.

The children had been seen at our clinic at least every sixth month for 3-6 yrs at the time of the present study. The following recordings were always made at each visit: number of hospital admissions due to acute severe asthma during the previous 6 months, age, height (Harpenden ${ }^{\circledR}$ stadiometer (Holtain Ltd., UK), mean of three measurements), weight and lung function (Vitalograph ${ }^{\circledR}$ (Vitalograph Ltd., Buckingham, UK), best of three measurements), use of concurrent medicine, dose of inhaled budesonide and inhalation device. Furthermore, adjustments of the dose of inhaled corticosteroid were made based upon the assessment of clinical control of the disease in order to treat the child with the minimal effective dose.

Between clinic visits, changes in budesonide dose or other asthma medications were always made under the supervision of the clinic so that transient changes in treatment during periods of increased asthma symptoms were always recorded.

These recordings made it possible to accurately calculate the average dose of exogenous corticosteroid during the previous 6 months and the accumulated dose of budesonide over the years.

Compliance with the asthma medication was checked at each visit by asking the child and the family about their compliance. In addition, the frequency of renewal of prescriptions was measured once a year for each child. Finally, the child was given an inhaler at the clinic whenever the inhaler strength was changed. In such situations, the child was asked to return to the clinic for another visit 6-8 weeks later and to bring the inhaler at that visit. These measures allowed an assessment of compliance by measuring the number of doses taken (weighing canisters (pressurized metered-dose inhaler; pMDI)) or counting the number of doses left (Turbuhaler®, Astra AB, Lund, Sweden) in relation to the prescribed dose.

All asthma medication except systemic corticosteroids for $>2$ weeks $\cdot \mathrm{yr}^{-1}$, were allowed in the study. Children who required systemic corticosteroid for $>2$ weeks $\cdot \mathrm{yr}^{-1}$ were excluded from the study.

In addition to children treated with inhaled budesonide, the ongoing prospective study also include a "control group" of children with asthma whose parents do not want their child to be treated with inhaled corticosteroids. These "controls" have been followed in exactly the same manner as the children on budesonide (similar recordings at least every 6 months at our clinic for a number of years). They receive all varieties of asthma medication, except inhaled or systemic corticosteroids, for $>2$ weeks. $\mathrm{yr}^{-1}$. In addition to these children, we have also included some newly referred children with asthma to the control group of the present study in order to obtain a sufficient number of patients for comparison. None of these newly referred children had ever received oral or inhaled corticosteroids for $>2$ weeks.

All children from the ongoing prospective study who had received inhaled budesonide continuously for $>3 \mathrm{yr}$ were included in the present study investigating the occurrence of PSCs, bruises and hoarseness. To avoid the confounding influence of systemic corticosteroids, the following exclusion criteria were used in the present study: $>14$ days treatment with systemic corticosteroids ever (both groups of children); inhaled corticosteroids for $>2$ weeks ever (control group); topical (skin) corticosteroids after the age of 2 yrs ever applied to $>25 \%$ of the body surface (both groups); metabolic diseases, such as diabetes (both groups); family history PSC; and use of nasal corticosteroids, except for the treatment of seasonal rhinitis $<1$ month $\cdot \mathrm{yr}^{-1}$ (both groups).

All patients were questioned about the occurrence of any incidents (trauma) in the past that might cause opacities of the lens.

\section{Cataract assessment}

A narrow-beam slit lamp examination was performed in all patients after dilation of the pupils. All examinations were carried out by the same experienced, specialist-certified ophthalmologist, who had no knowledge of the treatment received by the children. Opacities, if present, were classified as PSC or non-PSC opacities. The latter included various lesions not related to corticosteroid therapy, such as nuclear sclerosis or congenital cataracts.

\section{Bruises}

The number and size of bruises on one forearm and one lower leg were recorded. The physical examinations were always done on the limbs of the dominant-hand side of the patient. Additionally, each family was asked to rate, using a visual analogue scale (0-10), their child's tendency to bruise $(0=$ not at all, $10=$ very easily $)$.

Since differences in physical activity between the two groups might influence the occurrence of bruises, an assessment of each patient's physical activity was made with the aid of a visual analogue scale and a standardized questionnaire about daily activities, including participation in sports (number of times per week). The visual analogue scale (0-10) scored the children's participation in play and daily physical activities within the previous month $(0=$ none at all, 10=very high level).

\section{Hoarseness}

All families were asked if their child experienced hoarseness or other noticable voice changes. The answer options were: "Yes", "No" or "Don't know".

The recordings of bruises and hoarseness were always done by a person who had no knowledge of the treatment received by the children.

The study was approved by the local ethics committee and all families had given verbal and written informed consent to participation.

\section{Statistical analysis}

Fisher's exact test (one-sided) was used to assess whether the PSC was more frequent in the budesonide group than in the control group. All answers provided by the families to the questions asked during the study were 
compared between groups using chi-square tests for homogeneity. The number and size of bruises in the two groups were compared by t-tests.

The relationship between bruises and the accumulated dose and total duration of treatment with budesonide was assessed only through scatter plots.

\section{Results}

A total of 268 children were studied: 157 in the budesonide group and 111 in the control group. The patients characteristics are shown in table 1 . The two groups were comparable with respect to age, height and weight. The proportion of males was somewhat higher, and the mean duration of asthma at the time of the study was significantly longer in the budesonide group than in the control group. Furthermore, children treated with budesonide had a higher forced expiratory volume in one second (FEV1) ( $\%$ predicted) than the children in the control group.

Eight per cent of the children in the budesonide group used inhaled long-acting $\beta_{2}$-agonists, and $2 \%$ used theophylline. In the control group, $15 \%$ used inhaled long-acting $\beta_{2}$-agonists, $22 \%$ used theophylline, $20 \%$ used sodium cromoglycate and $1 \%$ used oral $\beta_{2}$-agonists. All children in both groups used inhaled $\beta_{2}$-agonists as needed. The mean compliance with inhaled budesonide was assessed to be $78 \%$ (range $42-110 \%$ ).

The mean total accumulated dose of budesonide for children in the budesonide group was $813.1 \mathrm{mg}$ (range 249-2,800 mg), and the mean treatment duration was 1,603 days (4.4 yrs) (range: 3-6 yrs), giving a mean average daily dose of $504 \mu \mathrm{g}$ (range: $189-1,322 \mu \mathrm{g}$ ).

\section{Cataracts}

Slit lamp examinations were not performed in six patients (two in the budesonide group and four in the control group) because the patients never visited the ophthalmologist despite repeated invitations. One patient in the budesonide group had a PSC (one eye only) that had already been diagnosed by another ophthalmologist 2 yrs prior to initiation of budesonide treatment. No other incidents of PSC were found in the two groups. Fisher's exact test did not find any increased risk of PSC in the budesonide group when compared with the control group $(p=0.46)$. Three children were diagnosed with non-PSC opacities: two children in the budesonide group showed signs consistent with congenital unilateral cataract and one child in the control group showed signs consistent with congenital bilateral cataract.

Table 1. - Patient characteristics of the two groups of children with asthma

\begin{tabular}{lcc}
\hline & Control group & Budesonide group \\
\hline Number & 111 & 157 \\
$\% \mathrm{M} / \% \mathrm{~F}$ & $55 / 45$ & $69 / 31$ \\
Age yrs & $9.9(5-16)$ & $10.3(5-16)$ \\
Height kg & $142(107-177)$ & $143(104-182)$ \\
Weight kg & $37.4(16-75)$ & $38.1(16-90)$ \\
Atopy \% & 86 & 89 \\
Asthma duration yrs & $4.5(0.5-12)$ & $8.3(4-16)$ \\
FEV1 \% pred & $81(60-97)$ & $97(76-106)$ \\
\hline
\end{tabular}

Data are presented as mean values and ranges. FEV1: forced expiratory volume in one second; M: males; F: females.
Twenty-five per cent of the children in both groups reported previous events (physical trauma of the eye) that might influence the occurrence of lens opacities.

\section{Bruises}

There were no statistically significant differences in the number of bruises between the two groups (BUD=3.3, controls $=3.2 ; \mathrm{p}=0.70$ ), area on arm and leg covered by bruises $\left(\mathrm{BUD}=10 \mathrm{~cm}^{2}\right.$, controls $\left.=10.1 \mathrm{~cm}^{2} ; \mathrm{p}=0.97\right)$, tendency to bruise as assessed using a visual analogue scale (BUD $=5 / 10$, controls $=5 / 10 ; p=0.98$ ) or by the answer to the question: "Does your child bruise easily?" (table 2). Furthermore, there was no correlation between the occurrence of bruises or tendency to bruise and duration of treatment, accumulated, or current dose of budesonide (fig. 1).

Table 2. - Answers to the question "Does your child bruise easily?"

\begin{tabular}{lccc}
\hline & No & Yes & Don't know \\
\hline Budesonide $(n=157)$ & $90(57)$ & $62(39)$ & $5(4)$ \\
Control group $(n=111)$ & $75(68)$ & $35(31)$ & $1(1)$ \\
\hline
\end{tabular}

Data presented as number of children and percentages in parenthesis. There was no statistically significant difference between the two groups $(\mathrm{p}=0.14)$.
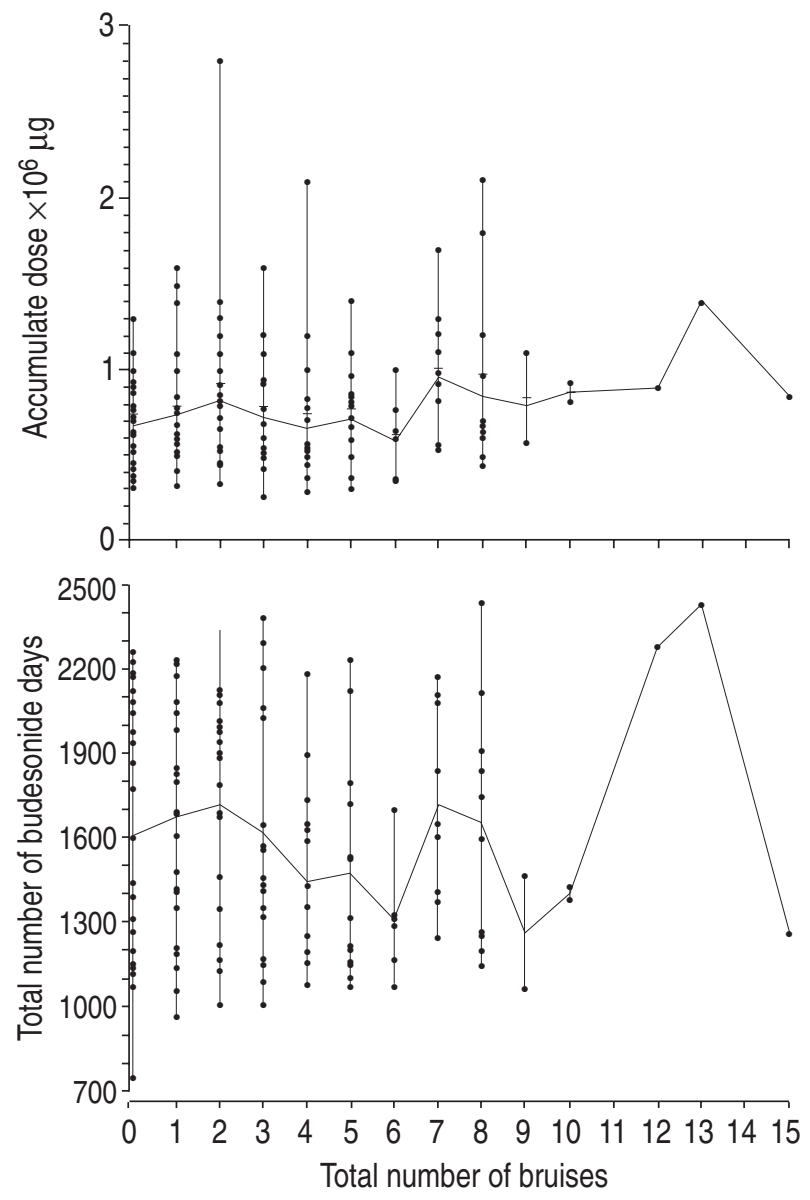

Fig. 1. - Total number of bruises as a function of accumulated dose and time on inhaled budesonide. No correlation was seen between the occurrence of bruises or tendency to bruise and duration of treatment of accumulated dose of budesonide. Solid line: geometric mean. 
Table 3. - Answers to the question "Does your child develop hoarseness or voice changes easily?"

\begin{tabular}{lrcc}
\hline & No & Yes & Don't know \\
\hline Budesonide $(\mathrm{n}=157)$ & $121(77)$ & $31(20)$ & $5(3)$ \\
Control group $(\mathrm{n}=111)$ & $87(78)$ & $23(21)$ & $1(1)$
\end{tabular}

Data presented as number of children and percentages in parenthesis. There was no statistically significant difference between the two groups $(\mathrm{p}=0.92)$.

The number of times per week that the children participated in sports activities was the same in both groups (1.46 (BUD) and 1.40 (control), respectively). However, based upon the results from the visual analogue scale, the children in the budesonide group were more physically active than the children in the control group (spent more hours outside playing, biked or walked to school more frequently, etc.), the mean scores in the two groups being 8.3 (BUD) and 5.7 (control) $(\mathrm{p}<0.01)$.

\section{Hoarseness}

There was no statistically significant difference between the two groups in occurrence of hoarseness or other noticable voice changes. This was reported in $20 \%$ in the budesonide group and $21 \%$ in the control group (table 3 ).

\section{Discussion}

The cataracts that complicate chronic systemic corticosteroid therapy are typically of the PSC type, although nuclear lesions may be seen as well $[8,16]$. The prevalence has been reported to be influenced by the daily and cumulative dose of corticosteroid and duration of treatment and probably also by patient age [5]. Furthermore, some researchers have suggested individual patient susceptibility as an important factor [17].

When designing the present study, we tried to avoid some of the problems of interpreting potential findings of opacities in the budesonide-treated children. This was achieved by restricting the study to well-characterized patients who we knew had never received systemic corticosteroids for $>14$ days, and by including a control group of children with asthma who had never received exogenous corticosteroids. This is clinically more relevant than a comparison with healthy children because cataracts may occur at a higher frequency in atopic patients in the anterior subcapsule, the posterior subcapsule or throughout the lenses [18-20]. In addition, the ophthalmologist was blinded with respect to the treatment given in order to minimize any possible bias. The only case of an earlierdiagnosed lens opacity was also detected during the study, indirectly supporting the quality of the slit lamp examination. It was not possible, however, to assess accurately whether the opacity in the posterior subcapsular region had progressed since the initial diagnosis, but it appeared not to be the case.

The pathogenesis of corticosteroid-induced PSC is not fully understood. Disturbances of carbohydrate metabolism have been suggested to play an important role. It is known that budesonide, given in the doses used in the present study, does not exert any major adverse influence on carbohydrate metabolism in children [21, 22]. Hence, if the theory about disturbed carbohydrate metabolism is accurate, we would not expect to find any PSC in the budesonide-treated group. This, indeed, was what we found. This finding corroborates with those reported in previously published studies of smaller groups of less well-characterized children, adolescent and adult patients treated for shorter periods of time with inhaled glucocorticosteroids $[5,17,23-25]$. These data strongly suggest that longterm treatment with budesonide in the doses used in the present study is unlikely to cause PSC formation. Furthermore, routine ophthalmological surveillance for PSC in children receiving long-term inhaled corticosteroid treatment is not warranted and probably not cost-effective.

The budesonide group differed from the control group with respect to duration of asthma at the time of study and to the proportion of males and females. These variables did not influence the parameters studied, so it is unlikely that these intergroup differences influenced the results.

To the best of our knowledge, the influence of inhaled corticosteroids on the occurrence of bruises has not previously been studied in children. High doses given for several years have been reported to increase bruising in adults, especially postmenopausal females. In these patients, there seems to be a correlation between bruises and the duration of treatment and accumulated dose $[9,10]$. In the present study, there was no difference in the occurrence of bruises or tendency to bruise between the two groups, despite the fact that the children in the budesonide group were more physically active than the children in the control group, a factor that would logically cause one to expect an increased number of bruises. Moreover, neither accumulated nor current budesonide dose, nor duration of treatment correlated with the occurrence of bruising. This strongly suggests that bruising is unlikely to be a problem in children receiving long-term treatment with inhaled corticosteroids in the doses used in the present study. This is in accordance with the findings of studies evaluating the influence of inhaled corticosteroids on markers of collagen formation and degradation in children [12-15]. Only high doses of inhaled corticosteroids seem to be associated with subtle changes in some of these markers, suggesting a reduced collagen turnover rate. It remains to be established, however, whether these short-term changes in markers of collagen formation and degradation are clinically important. The present findings suggest that they are not.

Bruising may be a relatively crude outcome measure. Ultrasound has recently been suggested as a useful tool in detecting subtle changes in the composition and texture of the skin caused by exogenous corticosteroids [26], but further studies are required to confirm the accuracy and clinical value of ultrasound for this purpose.

The frequency of hoarseness of around $20 \%$ in the budesonide group is in agreement with the findings of many studies in mainly adult patients [11, 27-32]. Hoarseness is normally assumed to be the most frequent adverse effect of inhaled corticosteroid treatment. Therefore, the absence of an increased occurrence in the budesonide group was very surprising. The interesting finding in this study was that the rate did not differ from the control group, emphasizing the importance of including a control group for comparison and perhaps also blinding the study 
to avoid bias. These precautions have not always been taken in other studies.

The lack of an increased occurrence of hoarseness in the budesonide group might be due to inaccurate or imprecise questioning of the patients. However, the questions that we posed to the families were quite similar to those used in other studies, so we do not have reason to believe that this caused the discrepancy. It may be that the inhalation device used in this investigation, the dry powder inhaler Turbuhaler ${ }^{\circledR}$, might have had a positive influence on hoarseness. Reports in the literature suggest that this device may reduce the occurrence of hoarseness as compared with a pMDI $[27,33]$, probably because the vocal cords are in a more open position when inhaling against a certain resistance $[34,35]$. The majority of reports on hoarseness have been in adults, who have been assessed rather early after initiation of treatment with inhaled corticosteroids. It is not known whether children and adults differ with respect to susceptibility to this possible adverse effect or whether voice changes are more frequent at the beginning of the treatment. Finally, the children in our study had received the therapy for several years and therefore may have become used to any possible voice changes.

It would have been desirable to have electronic monitoring of compliance to accurately assess the actual dose taken. That was not possible, mainly because we could not obtain a Turbuhaler with an electronic recording of the number of doses taken. Therefore, we had to monitor compliance in a less accurate way. However, during a $1 \mathrm{yr}$ period, we were able to electronically monitor the actual number of doses taken in some of the patients. These measures were in reasonably good agreement with our other recordings (the mean compliance was the same). This suggests that our compliance estimate was fairly accurate. This assumption is indirectly supported by the excellent clinical results seen in the budesonide group [1].

\section{Conclusion}

We conclude that three to six years' treatment of children with inhaled budesonide at an average daily dose of about $500 \mu \mathrm{g}$ is not associated with an increased occurrence of posterior subcapsular cataracts, bruises, tendency to bruise, hoarseness or noticeable voice changes in children with chronic asthma.

\section{References}

1. Agertoft L, Pedersen S. Effects of long term treatment with an inhaled corticosteroid on growth and pulmonary function in asthmatic children. Respir Med 1994; 88: 373-381.

2. Barnes PJ, Pedersen S. Efficacy and safety of inhaled corticosteroids in asthma. Am Rev Respir Dis 1993; 148: 126.

3. British Thoracic Society, National Asthma Campaign, Royal College of Physicians, British Association of Accident and Emergency Medicine, British Paediatric Society, Royal College of Paediatrics and Child Health. The British Guidelines on Asthma Management. Thorax 1997; 52: $1-21$.

4. Pedersen S. Inhalers and nebulizers, which to choose and why. Respir Med 1996; 90: 69-77.
5. Toogood JH, Markov AE, Baskerville J, Dyson C. Association of ocular cataracts with inhaled and oral steroid therapy during long-term treatment of asthma. J Allergy Clin Immunol 1993; 91: 571-579.

6. Levy HB. Effect of inhaled corticosteroids on the risk of cataract formation in patients with steroid-dependent asthma. Ann Pharmacother 1996; 30: 1324-1327.

7. Rooklin AR, Lampert SI, Jaeger EA, McGeady SJ, Mansmann HC, Jr. Posterior subcapsular cataracts in steroidrequiring asthmatic children. J Allergy Clin Immunol 1979; 63: 383-386.

8. Bhagat RG, Chai H. Development of posterior subcapsular cataracts in asthmatic children. Pediatrics 1984; 73 : 626-630.

9. Roy A, Leblanc C, Paquette L, et al. Skin bruising in asthmatic subjects treated with high doses of inhaled steroids: frequency and association with adrenal function. Eur Respir J 1996; 9: 226-231.

10. Mak V, Melchor R, Spiro SG. Easy bruising as a side effect of inhaled corticosteroids. Eur Respir J 1992; 5: 1068-1074.

11. Williamson IJ, Matusiewicz SP, Brown PH, Greening AP, Crompton GK. Frequency of voice problems and cough in patients using pressurized aerosol inhaled steroid preparations. Eur Respir J 1995; 8: 590-592.

12. Wolthers O, Juul A, Hansen M, Müller J, Pedersen S. The insulin-like growth factor axis and collagen turnover in asthmatic children treated with inhaled budesonide. Acta Paediatr 1995; 84: 393-397.

13. Wolthers O, Juul A, Hansen M, Müller J, Pedersen S. Growth factors and collagen markers in asthmatic children treated with inhaled budesonide. Eur Respir J 1993; 6: Suppl. 17, 261.

14. Wolthers OD, Hansen M, Juul A, Nielsen HK, Pedersen $\mathrm{S}$. Knemometry, urine cortisol excretion and measures of the insulin-like growth factor axis and collagen turnover in the assessment of systemic activity of inhaled corticosteroids. Pediatr Res 1997; 41: 44-50.

15. Birkebaek NH, Esberg G, Andersen K, Wolthers O, Hassager $\mathrm{C}$. Bone and collagen turnover during treatment with inhaled dry powder budesonide and beclomethasone dipropionate. Arch Dis Child 1995; 173: 524-527.

16. Spaeth GP, Von Smallman L. Corticosteroids and cataracts. Int Ophthalmol Clin 1966; 16: 915-929.

17. Simons FER, Persaud MP, Gillespie CA, Cheang M, Shuckett EP. Abscence of posterior subcapsular cataracts in young patients treated with inhaled glucocorticoids. Lancet 1993; 342: 776-778.

18. Massarano AA, Hollis S, Devlin J, David TY. Growth in atopic eczema. Arch Dis Child 1993; 68: 677-679.

19. Amemiya T, Matsuda H, Uehara M. Ocular findings in atopic dermatitis with special reference to the clinical features of atopic cataract. Ophthalmologica 1980; 180: 129-132.

20. Castrow FF. Atopic cataracts versus steroid cataracts. $\mathrm{Br}$ J Ophthalmol 1981; 5: 64-66.

21. Wolthers OD, Pedersen S. Carbohydrate metabolism, serum proteines and peripheral cell counts in asthmatic children treated with prednisolone or inhaled budesonide. Eur Respir J 1994; 17: 449.

22. Turpeinen M, Sorva R, Juntunen-Backman K. Changes in carbohydrate and lipid metabolism in children with asthma inhaling budesonide. J Allergy Clin Immunol 1991; 88: 384-389.

23. Abuekteish F, Kirkpatrick JN, Russell G. Posterior subcapsular cataract and inhaled corticosteroid therapy. Tho$\operatorname{rax} 1995$; 50: 674-676. 
24. Sevel D, Weinberg EG, van Niekerk CH. Lenticular complications of long-term steroid therapy in children with asthma and eczema. J Allergy 1977; 60: 215-217.

25. Nassif E, Weinberger M, Sherman EA. Extrapulmonary effects of maintenance corticosteroid therapy with alternate-day prednisone and inhaled beclomethasone in children with chronic asthma. J Allergy Clin Immunol 1987; 80: 518-529.

26. Korting HC. Topical glucocorticoids and thinning of normal skin as to be assessed by ultrasound. Curr Probl Dermatol 1993; 21: 114-121.

27. Selroos O, Backman R, Forsen KO, et al. Local sideeffects during 4-year treatment with inhaled corticosteroids - a comparison between pressurized metered-dose inhalers and Turbuhaler. Allergy 1994; 49: 888-890.

28. Müns G, Bergmann KC. Local and systemic side effects of inhalatory corticosteroids - what has been confirmed? Pneumologie 1993; 47: 201-208.

29. Williams J, Cooper S, Wahedna I, Wong CS, MacFarlane JT. Inhaled steroids and their effects on voice and throat a questionnaire survey. Am Rev Respir Dis 1992; 145: A741.
30. Matusiewicz S, Williamson I, Brown P, Greening AP, Crompton GK. A survey of voice problems and cough in patients taking inhaled aerosol corticosteroids. Eur Respir J 1991; 4: Suppl. 14, 484s.

31. Settipane GA, Kalliel JN, Klein DE. Rechallenge of patients who developed oral candidiasis or hoarseness with beclomethasone dipropionate. $N$ Engl Reg Allergy Proc 1987; 8: 95-97.

32. Hone SW, Donnelly MJ, Robertson J, Coakley R, O'Neill S, Walsh MJ. Dysphonia and inhaled steroids: a prospective study. Rev Laryngol Otol Rhinol 1996; 117: 331-333.

33. Pauwels RA, Hargreave FE, Camus P, Bukoski M, Stohl E. A 1-year comparison of Turbuhaler vs pressurized metered-dose inhaler in asthmatic patients. Chest 1996; 110: 53-57.

34. Dewar MH, Matusiewicz SP, Ning A, et al. Comparison of pMDI plus Nebuhaler and Turbohaler in asthmatic patients with dysphonia. Thorax 1996; 51: A74

35. Vogel H, Wettmarshausen C. Immediate effects of glucocorticoid inhalations via MDI and via Turbuhaler - a digital X-ray study. Pneumologie 1995; 49: 559-560. 